\title{
A mensuração do desempenho de ministérios e agências de governo: evoluções internacionais"
}

\section{Colin Talbot, Lyn Daunton e Colin Morgan}

\section{Introdução}

Este relatório foi preparado para o National Audit Office - NAO (Gabinete Nacional de Auditoria), do Reino Unido, para inclusão como apêndice no próximo relatório do $N A O$ sobre o uso da mensuração do desempenho pelos ministérios do governo central do Reino Unido, que será apresentado ao Committee of Public Accounts (Comitê das Contas Públicas do Parlamento).

O relatório foi compilado pelos escritórios de pesquisa sobre o desenvolvimento da mensuração do desempenho em oito países: Austrália, Canadá, Dinamarca, Finlândia, Holanda, Nova Zelândia, Suécia e nos Estados Unidos. Estes países foram escolhidos porque conheceram níveis relativamente altos de atividade e de experiência na mensuração do desempenho e pela diversidade de experiências.

O relatório restringiu-se principalmente à documentação disponível em inglês, por causa das restrições de tempo e de outros recursos. Portanto, para os países de outras línguas que não o inglês, a informação não será tão completa como deveria.

A análise é restrita ao nível nacional ou federal, o que não significa que este seja o único ou o mais importante nível em que a mensuração do desempenho esteja ocorrendo. Nem é o nível federal que está necessariamente conduzindo a mudança - na Austrália, por exemplo, ele obviamente liderou, enquanto que nos Estados Unidos foram os governos locais e estaduais que desenvolveram independentemente seus sistemas, e em alguns casos antes mesmo do governo federal. O nível federal foi selecionado principalmente pela facilidade de comparação, tanto entre as jurisdições quanto com o estudo do Reino Unido.

Colin Talbot, Lyn Daunton e Colin Morgan são professores de Política Pública e de Administração da Universidade de Glamorgan,

País de Gales,

Reino Unido.

Contato: info@ publicfutures.com

Traduzido por René Loncan Filho 
O que é principalmente relatado é o que os governos dizem estar fazendo em relação à mensuração do desempenho, que nem sempre coincide com o que está realmente sendo implementado. Uma "corretiva" particularmente útil tem sido a avaliação crítica dos sistemas de desempenho implementados pelas instituições superiores de auditoria em cada país. Estes exames têm freqüentemente sublinhado as diferenças entre as políticas declaradas e a implementação.

As perguntas abordadas na pesquisa são:

- Qual é o contexto geral dentro do qual a mensuração do desempenho é implementada?

- Quem é responsável pela mensuração do desempenho e de sua prestação de contas?

- Quais são os objetivos de alto nível da mensuração do desempenho e de seu sistema de prestação de contas?

- O que está sendo medido e que tipo de medidas estão sendo usadas?

- As medidas de mensuração transversais são usadas?

- Como é garantida a qualidade da informação?

- Quem pode ser responsabilizado pelo desempenho?

- Como é feita a prestação de contas sobre o desempenho para o público?

-Quais são os principais desenvolvimentos atuais?

Existem, obviamente, muitas outras perguntas que poderiam ser feitas, mas estas proporcionam um importante escopo para a comparação com os desenvolvimentos verificados no Reino Unido.

\section{Qual é o contexto geral dentro do qual a mensuração do desempenho é implementada?}

Nesta seção, faremos uma breve introdução sobre cada país examinado, procurando identificar os desenvolvimentos da mensuração do desempenho no contexto das reformas gerais da gestão pública.

A título de recordação do peso relativo do setor público em cada país e no Reino Unido, a Tabela 1 estabelece as proporções econômicas e de emprego do setor público. Como pode ser observado, existem muitas variações nas proporções econômicas da maior participação da despesa pública (Suécia), que corresponde a praticamente o dobro do que a menor (Estados Unidos). Dentro destas macrocifras, também é importante lembrar que existem grandes diferenças nos arranjos constitucionais, no governo, nas estruturas e nos papéis dos serviços públicos — sem mencionar, obviamente, as culturas políticas. 
Tabela 1: Proporções relativas dos setores públicos (organizadas pela dimensão econômica)

\begin{tabular}{|c|c|c|c|c|}
\hline País & $\begin{array}{l}\text { Despesas } \\
\text { gerais } \\
\text { correntes do } \\
\text { governo } \\
\text { como } \\
\text { porcentagem } \\
\text { do PIB }\end{array}$ & Ano & $\begin{array}{c}\text { Empregos do } \\
\text { governo } \\
\text { como } \\
\text { porcentagem } \\
\text { do emprego } \\
\text { total }\end{array}$ & Ano \\
\hline Nova Zelândia & $(\mathrm{n} / \mathrm{a})$ & & 22,1 & 1991 \\
\hline Estados Unidos & 34,3 & 1995 & 13,4 & 1995 \\
\hline Austrália & 35,6 & 1995 & 16,0 & 1995 \\
\hline Reino Unido & 42,3 & 1994 & 14,1 & 1995 \\
\hline Canadá & 45,8 & 1995 & 19,6 & 1995 \\
\hline Holanda & 50,0 & 1996 & 11,9 & 1995 \\
\hline Finlândia & 55,9 & 1995 & 25,2 & 1995 \\
\hline Dinamarca & 59,6 & 1995 & 30,7 & 1995 \\
\hline Suécia & 63,8 & 1995 & 31,2 & 1995 \\
\hline
\end{tabular}

Fonte: Adaptado de Contas Nacionais, OCDE, Paris, 1998.

No período principalmente coberto por este relatório — os anos 90 - as taxas de crescimento econômico entre nossa amostra também variaram consideravelmente (ver Tabela 2). Quatro países - Austrália, Estados Unidos, Holanda e Dinamarca — tiveram desempenhos superiores à média da Organização para Cooperação e Desenvolvimento Econômico (OCDE), enquanto que os outros quatro - Canadá, Finlândia, Nova Zelândia e Suécia - tiveram desempenhos inferiores. O alcance dos desempenhos econômicos é marcante - as taxas mais baixas sendo de apenas um quarto das mais altas.

Isto sugere, fortemente, que não há um fator econômico óbvio comum sublinhando o ímpeto em relação à reforma da gestão pública, em geral, ou o enfoque nos desempenhos no setor público em particular. É claro que o crescimento econômico não é somente um fator sócioeconômico que pode levar a acentuadas pressões sobre o desempenho do setor público - mudar os perfis de tributação; mudanças demográficas; aumentar o nível da demanda por serviços etc. poderiam igualmente contribuir. Isto também não implica que os problemas econômicos (por exemplo, a Suécia em meados dos anos 90) não figuravam de forma proeminente na causa de mudanças em países específicos (ver Pollitt e Bouckaert, 2000, para uma discussão mais completa de algumas destas questões). 
Tabela 2: Taxas de crescimento

\begin{tabular}{l|c}
\hline País & Crescimento atual do PIB per capita 1990-98 \\
\hline Austrália & 2,3 \\
\hline Estados Unidos & 2,0 \\
\hline Holanda & 2,0 \\
\hline Dinamarca & 1,9 \\
\hline Reino Unido & 1,7 \\
\hline Média da OCDE & 1,2 \\
\hline Canadá & 1,1 \\
\hline Finlândia & 1,0 \\
\hline Nova Zelândia & 0,7 \\
\hline Suécia & 0,6 \\
\hline
\end{tabular}

Fonte: adaptado de Sarpetta, Bassanini et al., 2000.

\section{Austrália}

A Austrália, assim como a Nova Zelândia, foi obrigada a distanciarse de políticas econômicas protecionistas nos anos 80 e vivenciou dificuldades econômicas sucessivas que, em consequiência, produziram pressões fiscais sobre os gastos públicos. A reforma da gestão pública foi conduzida pelo nível federal (Commonwealth).

A Austrália tem sido, portanto, muito ativa na reforma da gestão pública ao longo das duas últimas décadas. O governo federal (Commonwealth) tem uma história relativamente longa de alguma forma de mensuração e de prestação de contas de "desempenho" em seu sentido mais amplo. Particularmente em 1988, teve início um programa rotativo de revisões de avaliações de todas as áreas da política e foram tomadas medidas para garantir que os resultados destas revisões fossem considerados nos processos de decisão orçamentária (Ministério das Finanças 1992; Ministério das Finanças 1994; Ministério das Finanças, 1995).

Mais recentemente, a introdução de contabilidade e de orçamentos baseados no crescimento tem sido ligadas à informação do desempenho sobre insumos e resultados para cada ministério ou agência. $\mathrm{O}$ alvo principal parece ter sido o de proporcionar informações sobre o desempenho de alto nível, ligadas a recursos mais precisos levados em consideração para que os julgamentos gerais de "custo-benefício" pudessem ser feitos. Este é o contexto de um governo empenhado em reduzir o tamanho do setor público e introduzir técnicas de gestão do estilo utilizado no setor privado (Pollitt e Bouckaert, 2000). 
A reforma do setor público canadense foi originalmente pressionada por sua situação fiscal insustentável. Em 1994, o déficit federal foi de 6\% do PIB; com o governo tendo que enfrentar uma carga crescente da dívida pública, a falta de credibilidade fiscal e o nervosismo do mercado financeiro refletiram-se em altas taxas de juros.

A ênfase na redução orçamentária era para ser baseada na redução das despesas e não no aumento dos impostos. Desde então, o Canadá teve um progresso significativo na restauração de sua situação fiscal. No biênio 1997/98, o governo alcançou o seu primeiro orçamento equilibrado em quase 30 anos.

A redução orçamentária e a reforma do setor público iniciaram-se pela Programme Review - 1994 (Revisão de Programas) — um exame abrangente de todos os programas do governo para estabelecer a maneira mais efetiva e mais eficiente em termos de custo para a prestação de programas e de serviços.

A partir da Programme Review, o governo introduziu um grande número de iniciativas, a mais significativa delas sendo o Getting Government Right, introduzida em 1996 com o objetivo de modernizar os programas federais e os serviços para atender às necessidades da população, tanto como cidadãos quanto como clientes.

A iniciativa Getting Government Right confirmou o compromisso do governo de mudar para uma cultura gerencial baseada em resultados ou nos desempenhos, tal como o projetado pela estratégia baseada no desempenho do governo federal em 1995, dentro do primeiro relatório ao Parlamento, produzido pelo Presidente do Conselho do Tesouro (Strengthening Government Review). A estratégia encorajou os ministérios e as agências a identificar os compromissos de resultados, as medidas, os relatórios e o uso das informações sobre os resultados e o desempenho. O relatório produzido pelo Presidente do Conselho do Tesouro é apresentado anualmente ao Parlamento.

\section{Dinamarca}

A Dinamarca — assim como a Finlândia e a Suécia — tem um dos maiores setores públicos como proporção de sua atividade econômica interna - com as despesas públicas girando em torno de 55\% do PIB em 1999 (OCDE). Nos anos 80, a Dinamarca sofreu crises econômicas e fiscais, e o enfoque das reformas foi principalmente direcionado para a redução dos gastos públicos. Durante a última década, o orçamento tendeu ao superávit, e nos últimos anos a dívida tem-se reduzido. Assim sendo, as medidas econômicas, em si, não foram a principal força direcional da reforma. 
Também deve ser lembrado que a Dinamarca tem uma estrutura

de governo altamente descentralizada, onde a maioria das despesas públicas e dos serviços são de responsabilidade dos governos locais e não do governo central.

As reformas da gestão pública na Dinamarca desenvolveram-se em torno de três orientações principais:

- Criar condições favoráveis para o aprendizado do setor público e para a experimentação;

- Ressaltar a eficiência, o serviço e a qualidade por meio de ferramentas gerenciais ligadas ao desempenho; e

- Dar poder aos cidadãos e aos usuários dos serviços públicos.

(Ver website da OECD/PUMA/Surveys 2000).

A reforma da gestão pública tem sido perseguida geralmente por meio da descentralização, juntamente com um direcionamento central, assessoria e apoio no desenvolvimento de ferramentas e de conceitos. Dentro deste contexto geral:

“A gestão do desempenho tem sido um elemento central nas reformas do setor público, desde o lançamento do Modernisation Programme (Programa de Modernização), em 1983. (OCDEPUMA, 1997).

As principais reformas específicas incluíram:

- Promover a mensuração do desempenho como parte do processo orçamentário;

- Criar "agências por contratos", com maior autonomia em relação a arranjos internos e mantidas por contratos de desempenho com seus ministros supervisores; e

- Iniciativas orientadas para a qualidade do serviço prestado.

\section{Finlândia}

A Finlândia tem um grande setor público e, assim como a Suécia, experimentou sérios problemas econômicos em meados dos anos 90.

A estrutura do governo central finlandês é similar ao modelo de agência central sueco e, como a Dinamarca, tem um grande setor de governo local com responsabilidades significativas pela prestação de serviços e muita autonomia formal (o governo local é responsável pela prestação de dois terços dos serviços públicos). Contudo, ao contrário da Dinamarca, o governo central finlandês tem tido, na prática, muito maior controle sobre o governo local. Similarmente, as agências centrais são muito mais centralmente controladas e dirigidas do que no caso da Suécia.

As principais reformas do setor público na Finlândia foram levadas a cabo entre 1987 e 1997, introduzindo mudanças substanciais na gestão financeira e na estrutura do setor estatal. 
As partes mais significantes do programa de reforma foram:

- A adaptação da programação orçamentária orientada para resultados e o sistema do desempenho (desde 1987, com sua implementação completa em 1994);

- A delegação de poderes na tomada de decisões sobre a gestão de recursos humanos para o nível da agência;

- A reforma do Estado foi delegada às municipalidades;

- A corporativização de um grande número de entidades estatais, convertendo-as em empresas estatais; e

- Reformas estruturais, tais como fusões, a reestruturação de agências estatais e a reorganização do nível provincial do governo.

Desde 1995, a gestão do desempenho tem sido aplicada à totalidade do governo central. A idéia por trás da reforma era enfatizar os resultados ao invés dos insumos e das regras e de melhorar a projeção de objetivos e seu acompanhamento. No processo, os contratos de desempenho tiveram um papel importante. $\mathrm{O}$ modelo contratual substituiu o antigo e hierárquico sistema de direcionamento e de controle baseado na complacência. As negociações de resultados e os contratos de desempenho representam maneiras descentralizadas e flexíveis de tornar as agências do governo mais conscientes dos custos, responsáveis e responsabilizáveis. A gestão do desempenho também tem sido considerada como um dos principais instrumentos para fortalecer o pensamento estratégico e a priorização de atividades pelos ministérios.

\section{Holanda}

O governo holandês consiste de várias minorias políticas, nenhuma delas tendo qualquer possibilidade real de tornar-se maioria. O governo, portanto, pode sempre ser baseado na coalizão e na cooperação.

Nos anos 80, a reforma do governo focalizou-se na necessidade de melhorar a coerência e a integração, com a ênfase sendo atribuída à busca de novos métodos e novas estruturas para o planejamento governamental e para a coordenação da tomada de decisões.

Nos anos 90, contudo, devido à necessidade de melhoria nas finanças públicas, a ênfase transferiu-se para o tamanho do governo e para como reduzi-lo. Durante o período de 1992 a 1994, foi empreendida uma análise das tarefas centrais do governo, visando identificar o negócio central dos ministérios do governo com uma visão de tarefas realocadas ou reduzidas.

\section{Nova Zelândia}

As reformas do setor público da Nova Zelândia foram amplamente vistas como as mais radicais dentre os países-membros da OCDE. Houve diversas privatizações, transformação de organismos estatais em corporações 
e reformas radicais - econômicas, fiscais e de bem-estar. Assim como com a Austrália, a principal força direcional para estas mudanças foi a mudança da posição econômica do país, com o colapso dos antigos arranjos protecionistas da Commonwealth com o Reino Unido, o crescimento das economias asiáticas do Sudeste etc. A Nova Zelândia viveu um crescimento lento e crises econômicas recorrentes no final dos anos 70 e 80 e — sendo um país pequeno com um PIB per capita relativamente baixo - estes choques econômicos foram sentidos fortemente no setor público.

Em 1989, a Nova Zelândia adotou um sistema de "contratos de desempenho" entre os ministros e os ministérios do governo - estes não são documentos legalmente obrigatórios, mas "acordos de desempenho" - Public Finance Act (Lei das Finanças Públicas - 1989). Estes contratos de desempenho focalizavam-se em especificar os resultados que cada ministério iria produzir. Estes resultados são vistos como sendo "adquiridos" pela Coroa, por meio do sistema de estimativas e voto. Os ministérios também são solicitados a publicar (ex ante) uma declaração detalhada dos objetivos, como parte de seu Department Forcast Report - DFR (Relatório Ministerial de Previsão), que é examinado por comitês seletos como parte do exame das estimativas. A Lei de 1989 orienta os ministérios a publicar anualmente uma Statement of Service Performance - SSP (Declaração do Desempenho do Serviço) que mostre, para cada tipo de resultado, o desempenho atingido em comparação com o desempenho previsto em sua declaração de objetivos e em comparação com a previsão de desempenho no $D F R$. Regras similares se aplicam às organizações da Coroa.

\section{Suécia}

Em meados dos anos 90, a Suécia viveu uma crise econômica que, em decorrência, gerou uma crise fiscal com déficits e dívida públicos ampliados. Restrições orçamentárias generalizadas foram acompanhadas de outras reformas das finanças públicas, tais como as projeções de programação orçamentária e o desenvolvimento de programações orçamentárias orientadas pelos resultados. Embora tenha ocorrido uma melhoria nas finanças públicas, permanece incerto se houve uma resolução de longo prazo das dificuldades fiscais (Pollitt e Bouckaert, 2000).

Neste contexto, a Suécia também vem tentando desenvolver uma melhor qualidade e uma melhor flexibilidade na prestação de serviços públicos, e a mensuração do desempenho está protagonizando um papel importante neste processo.

O sistema central do governo sueco é fortemente baseado na forma de "agência", com pequenos ministérios e grandes agências. Isto se reflete na maneira pela qual a mensuração do desempenho se desdobrou. 
Embora a economia americana tenha se comportado razoavelmente bem na maior parte dos anos das duas últimas décadas, com apenas modestas diminuições no crescimento, a posição fiscal dos Estados Unidos se enfraqueceu consideravelmente no final dos anos 80 e começo dos anos 90. Grandes déficits orçamentários federais pareciam ser acompanhados de crises em um grande número de áreas de políticas públicas (crime, saúde, educação) e a extensa alienação do processo político (os Estados Unidos têm uma das taxas mais baixas de participação dentre os países-membros da OCDE). As fontes destas dificuldades - especialmente os problemas fiscais - são discutíveis, mas é razoável sugerir que elas têm mais a ver com escolhas políticas (despesas com defesa, reduções de impostos etc.) do que com condições econômicas latentes.

Os Estados Unidos também têm arranjos constitucionais muito diferentes (no nível federal) dos arranjos do Reino Unido ou da maioria dos outros países em nossa amostra. A separação dos poderes entre o Legislativo e o Executivo leva a algumas diferenças interessantes na programação orçamentária e em questões de desempenho. Os processos mais transparentes dos Estados Unidos, para a programação orçamentária e para a projeção de metas de desempenho (ver a seguir), são, parcialmente, o resultado do papel do Congresso na autorização de orçamentos propostos pelo setor Executivo - Office of Management and Budget (Escritório de Gestão e Orçamento).

\section{Quem é responsável pela mensuração do desempenho e por sua prestação de contas?}

Esta seção indica quem é responsável pela projeção e pela continuidade da política, pela produção e pela publicação da informação sobre o desempenho. Na maioria dos casos, esta é, obviamente, a organização competente, mas este não é necessariamente o caso. No governo local do Reino Unido, por exemplo, as autoridades individuais produzem dados de desempenho de acordo com as metas projetadas centralmente pela Audit Comission (Comissão de Auditoria), que também compara e publica a informação.

\section{Austrália}

Orientações para a Specifying Outcomes and Outputs, 1998 (Especificação dos Resultados e dos Impactos) e para os Outcomes and Outputs, 1999 (Resultados e Impactos) foram publicadas pelo 
Departament of Finance and Administration - DOFA (Ministério das

Finanças e da Administração da Commonwealth), que estabelecem as responsabilidades para a prestação de contas do desempenho. Estas orientações tinham como finalidade serem usadas em uma revisão em larga escala dos resultados e dos impactos, tais como os contidos na documentação orçamentária, que por sua vez resultou da Review of Budget Estimates (Revisão Orçamentária das Estimativas de Produção).

As agências, desejando mudar os resultados e a informação do desempenho a elas ligados, fazem-no por meio de um acordo com o ministro supervisor. Estas mudanças não necessitam de autorização do ministro do $D O F A$, por mais que eles, porventura, queiram consultar o $D O F A$ como um importante stakeholder. Contudo, se uma agência deseja alterar os impactos, é necessária a consulta e uma aprovação do ministro do DOFA.

Estes documentos tornam claro que a responsabilidade pela gestão do desempenho e a informação sobre o desempenho cabem, principalmente, às agências, com base nos princípios desenvolvidos pelo DOFA. A responsabilidade pela informação sobre o desempenho reside, principalmente, nos ministérios e agências do setor público, que têm o dever estatutário de produzi-lo sob a Financial Management and Accountability - FMA (Lei de Gestão Financeira e Responsabilização) 1997, que delegou responsabilidade para a tomada de decisões aos presidentes executivos das agências. Os presidentes executivos das agências têm responsabilidades para com seu ministro supervisor.

\section{Canadá}

A Tresury Board Secretariat - TBS (Secretaria da Junta do Tesouro) tem a responsabilidade geral pela gestão do desempenho, e desenvolve e gerencia as iniciativas de reformas. As iniciativas canadenses têm sido fortemente orientadas pela $T B S$ por meio de requerimentos formais encaminhados aos ministérios e às agências. Também existiram elementos encorajadores e facilitações, em vez de elementos de orientação por parte da $T B S$, além de algumas iniciativas "de baixo para cima" no interior das organizações federais.

Duas iniciativas principais começaram em 1994:

- A revisão de programas; e

- Melhorias no repasse de informações ao Parlamento.

Os ministérios foram encorajados a publicar mais informações de desempenho, principalmente por meio de maneiras inovadoras e acessíveis, tais como os sites da Internet.

Um novo Expenditure Management System - EMS (Sistema de Gestão de Despesas) foi introduzido, o qual passou a requerer que os 
Ministérios incorporassem as informações de desempenho na política de desenvolvimento e no melhoramento da prestação dos programas. Eles também devem incorporar o desempenho à revisão de programa e aos planos de negócios.

O sistema de mensuração do desempenho e de prestação de contas foi gradualmente se espalhando por todos os ministérios e todas as agências, e os relatórios anualmente submetidos ao Parlamento pelo Presidente da TBS expandiram-se consideravelmente. O Parlamento também fez mudanças consideráveis no processo orçamentário, visando incluir as metas de desempenho e seus resultados no processo de elaboração das estimativas e de avaliação pelos comitês. As consultas entre a TBS, o Parlamento e as entidades federais, sobre quais informações de desempenho deveriam ser coletadas e relatadas, parecem ter sido relativamente extensas.

$\mathrm{O}$ resultado foi que a responsabilidade pelo relatório de desempenho é dividida entre a TBS e as entidades federais (os ministérios e as agências devem relatar principalmente "de forma pública", enquanto que a $T B S$ confronta e relata especificamente ao Parlamento por meio do TBS President's Annual Report - Relatório Anual do Presidente da TBS).

\section{Dinamarca}

A responsabilidade geral cabe ao Ministério das Finanças. As iniciativas freqüentemente vêm de cima, mas são implementadas pela persuasão e por incentivos, antes do que pelo comando. As iniciativas "de baixo para cima" também são apoiadas por melhores diretrizes práticas e outras assistências. A Agency for Financial Management and Administrative Affairs (Agência para a Gestão Financeira e Assuntos Administrativos) tem a responsabilidade geral pelas reformas e pelo desenvolvimento das iniciativas.

\section{Finlândia}

A estrutura básica da reforma vem de cima, junto com linhas diretrizes e princípios, com o Ministério das Finanças orientando as reformas, e desenvolvendo novos métodos e princípios. O Public Management Institute (Instituto da Gestão Pública) proporciona apoio com o oferecimento de consultorias e treinamentos.

Os acordos sobre resultados anuais entre os ministérios e as agências projetam as metas de desempenho.

\section{Holanda}

O Ministério das Finanças é responsável pela mensuração e pela prestação de contas do desempenho. O Ministry of Home Affairs (Ministério 
dos Assuntos Internos) inicia os esquemas de modernização e estimula o desempenho nos governos locais.

Sob o Government Account Act (Lei de Contas do Governo), as organizações do governo são solicitadas a proporcionar a informação sobre o desempenho. Além destes requerimentos formais, existem projetos iniciados em uma base ad hoc, muitos dos quais provêm das agências e dos governos locais.

O Tribunal de Contas holandês tem um papel significativo em termos de auditoria do desempenho.

\section{Nova Zelândia}

Os ministérios e os Crown Entities (Departamentos da Coroa) são responsáveis pela publicação de seus resultados de desempenho - no caso dos ministérios, eles devem publicar uma $S S P$ em seus relatórios anuais.

\section{Suécia}

O Ministério das Finanças tem a responsabilidade geral pelo desenvolvimento dos sistemas de mensuração do desempenho, mas devido à forte posição das agências suecas, elas detêm um papel muito importante e de grande autonomia. Isto levou à conclusão de que "a documentação que o governo recebe das agências, como uma base para a sua revisão de atividades, ainda não é perfeitamente satisfatória" (citado no survey sobre o país, OCDE, 2000).

\section{Estados Unidos da América}

A divisão de poderes no sistema federal dos Estados Unidos significa que "o Presidente propõe e o Congresso dispõe". A situação atual é bem mais complexa. Sob o Government Performance and Results Act GPRA (Lei de Desempenho e Resultados do Governo), cada ministério e agência do governo federal (usaremos apenas "agências" para simplificação) é solicitado a produzir planos estratégicos, planos anuais de desempenho e relatórios de desempenho. Juntos, estes elementos criam um ciclo recorrente de planejamento, de execução de programa e de prestação de contas. O Office of Management and Budget - OMB (Gabinete da Gestão e do Orçamento) emite um documento de orientação anual (Circular A-11) que gere o conteúdo destes elementos. O OMB é requisitado a produzir um plano de desempenho para todo o governo.

Os planos de desempenho, assim como os planos estratégicos, os relatórios anuais e os relatórios de desempenho, são submetidos aos comitês de dotação do Congresso responsáveis pelos orçamentos dos ministérios, assim como aos comitês de autorização do Congresso. 
Assim sendo, a responsabilidade pela projeção da meta de desempenho é dividida entre as agências (que inicialmente propõem suas próprias metas), o $O M B$ (que consulta sobre elas) e o Congresso (que finalmente as aprova). Mesmo que a GPRA tenha sido aprovada em 1993, o processo de implementação foi deliberadamente lento (incluindo julgamentos substanciais dos métodos usados) e ainda está em processo de análise.

Como parte do processo de exame destes planos de desempenho, o General Accounting Office - GAO (Gabinete de Contabilidade Geral) — basicamente o equivalente americano do NAO inglês — produz um exame de cada plano individual, junto com um comentário geral e uma análise da qualidade e da validade dos planos. Esta análise focaliza-se em se os planos de mensuração do desempenho refletem com sucesso os planos estratégicos das agências ou não, se eles implementam uma melhoria em relação aos planos de anos anteriores e se pode haver confiança na informação de desempenho resultante.

\section{Resumo}

Geralmente a questão da responsabilidade pelo desempenho é complexa. Existem vários atores - entidades parlamentares ou outras entidades de autorização, o próprio governo (incluindo o tesouro/finanças e outros ministérios centrais), ministérios, agências etc. Em todos os casos, a responsabilidade pelo desempenho é inevitavelmente compartilhada, e a questão real é onde reside o equilíbrio específico com relação às diferentes jurisdições.

A responsabilidade pela mensuração do desempenho pode ser resumida em um certo número de aspectos:

- O grau de obrigatoriedade conferido às organizações para produzirem a informação sobre o desempenho - que é forte em alguns países (por exemplo, Canadá, Nova Zelândia e Estados Unidos) e fraco em outros (por exemplo, Holanda). Onde a compulsoriedade é forte, a responsabilidade cabe tanto às organizações que obrigam como às organizações responsabilizadas.

- O grau de especificação e de orientação nos tipos de informação de desempenho - que, mais uma vez, é forte e detalhado em alguns casos (por exemplo, na Nova Zelândia e Austrália) e mais flexível em outros (por exemplo, nos Estados Unidos e na Holanda).

- A força dos incentivos (e das penalidades) para o desempenho atual alcançado - onde estes são fortes, freqüentemente sob a forma de acordos de desempenho, a responsabilidade pela gestão do desempenho claramente reside mais firmemente no ministério/agência (por exemplo, a Nova Zelândia). 


\section{Quais são os objetivos de alto nível?}

Esta seção procura expor os objetivos do próprio sistema de mensuração do desempenho. Isto cobre tanto a finalidade da mensuração do desempenho (por exemplo, para a responsabilização ou para a gestão, ou ambos) quanto, em certa dimensão, o conteúdo (por exemplo, os resultados, os impactos etc.) dos sistemas de mensuração do desempenho, que também são abordados na seção seguinte.

\section{Austrália}

A Austrália tem tido, desde 1988, uma história apreciável, no nível do governo federal, de atenção às questões de avaliação de políticas e de programas. As reformas mais recentes do final dos anos 90 têm se concentrado em questões mais relacionadas à economia e à eficiência. Particularmente, a onda mais recente de reformas tem sido explicitamente direcionada no sentido de enfatizar um governo baseado em resultados e no desenvolvimento de práticas de trabalho similares aos da iniciativa privada, incluindo a privatização, a terceirização, a introdução de ofertas competitivas, a contabilidade incremental, assim como a focalização em resultados.

As mudanças relacionadas aos objetivos de alto nível da mensuração do desempenho concentram-se, portanto, na mensuração de resultados no âmbito de uma teoria de contabilidade incremental, visando proporcionar decisões de alocações (quanto à continuidade, abandono ou privatização de determinadas atividades). Contudo, a orientação estabelecida pelo DOFA acentua a mensuração tanto dos resultados (o que proporciona a informação de gestão) quanto dos impactos (proporcionando informação para a prestação de contas).

Recentemente, o auditor-geral da Austrália, em um discurso, levantou o problema da integração das questões de cumprimento (no sentido dos valores tradicionais do setor público de eqüidade, igualdade, ética etc.) com o desempenho - no sentido mais gerencial - (Barrett, 2000). Contudo, o DOFA encoraja as agências a monitorar e a reportar utilizando-se da comparação de uma série de indicadores de desempenho que cobrem a "conformidade com as regras e valores" e o "desempenho". Eles são, então, considerados como um todo em relação ao resultado ou ao impacto da agência, dando uma imagem mais exata de seu sucesso.

\section{Canadá}

Os sistemas de mensuração do desempenho têm sido usados como parte de uma estratégia geral para reduzir o déficit orçamentário do Canadá. Contudo, a forte ênfase que vem sendo dada desde 1994 em 
reportar ao Parlamento, tem proporcionado uma importante responsabilização pública e uma dimensão governamental para a prestação de contas do desempenho no Canadá.

Também é claro que a ênfase na mensuração do desempenho e em sua prestação de contas evoluiu com o passar do tempo, transformandose em um componente muito mais central de todos os processos de tomada de decisões sobre os recursos e as políticas, enquanto que também ficou muito mais sofisticada.

Em 1999, o President's Annual Report — Managing for Results 1999 (Relatório Anual do Presidente da TBS - Gerenciando por Resultados) integrou questões de desempenho e:

- Controle;

- Colaboração interministerial e intergovernamental;

- Relatórios mais abrangentes, incluindo os resultados (indicadores sociais); e

- Uma responsabilização e uma prestação de contas ao Parlamento aperfeiçoadas.

Isto significa que agora o Canadá tem um conjunto muito abrangente de objetivos de alto nível para a sua mensuração do desempenho e para seu sistema de prestação de contas. O ciclo completo está projetado na Figura 1.

\section{Figura 1: O ciclo parlamentar sobre o}

\section{desempenho, as estimativas e suprimentos}

\begin{tabular}{l|l|l}
\hline Outono & $\begin{array}{l}\text { Início das consultas } \\
\text { pré-orçamentárias }\end{array}$ & $\begin{array}{l}\text { O Pacote do Desempenho do } \\
\text { Outono é apresentado ao Parlamento: } \\
\text { - Gestão por resultados } \\
\cdot \text { Relatórios de desempenho ministerial } \\
\text { - Contas públicas } \\
\text { Os comitês revisam os Relatórios de } \\
\text { Desempenho Ministeriais e fazem } \\
\text { recomendações. }\end{array}$ \\
\hline Inverno & Orçamento & Principais Estimativas (Partes I e II) \\
\hline Primavera & $\begin{array}{l}\text { Relatórios Ministeriais } \\
\text { sobre Planos e }\end{array}$ & $\begin{array}{l}\text { Comitês } \\
\cdot \text { Relatório sobre as Estimativas } \\
\text { Prioridades }\end{array}$ \\
& Suprimentos recomendações sobre os \\
\hline Verão & Suprimento Completo & \\
\hline
\end{tabular}

Fonte: Adaptado do President of the Tresaury Board, Canadá 1999.

\section{Dinamarca}

Os objetivos do sistema de desempenho na Dinamarca têm variado ao longo do tempo, com o primeiro enfoque sendo dirigido à economia 
(contenção de gastos e cortes de custos), enquanto que, posteriormente, a

ênfase dirigiu-se para questões de maior "eficiência alocativa". Ao longo deste processo houve uma preocupação em aumentar as capacidades gerenciais das agências e um enfoque nos clientes e na qualidade do serviço. A combinação adotada, composta por uma relativamente fraca obrigatoriedade e por uma abordagem mais acessível, significa que as variações nas abordagens individuais são justificadamente amplas.

\section{Finlândia}

O primeiro enfoque da mensuração do desempenho na Finlândia foi o de introduzir mudanças organizacionais e culturais, e de tornar a administração mais eficiente, transparente e orientada para o serviço.

Esta estratégia geral foi reforçada pela resolução do governo Good Governance, High-Quality Services and Responsive Civic SocietyGuidelines for the Policy of Governance (Boa Governança, Serviços de Alta Qualidade e Sociedade Civil Responsiva - Diretrizes para a Política de Governança) 1998, que, por sua vez, também está ligada ao uso extensivo de cartas de serviço e de teorias de desempenho ou de qualidade (especialmente o Modelo Europeu de Qualidade e o Balanced Scorecard).

\section{Holanda}

A abordagem básica da mensuração do desempenho e da gestão tem sido conduzida centralmente e orientada para a regulamentação legislativa. O primeiro requisito para que a informação de desempenho fosse incluída nos processos orçamentários foi a Lei das Contas do Governo de 1976, que foi emendada em 1992 e em 1995. A mensuração do desempenho foi, de forma geral, vista como um instrumento que contribui para a melhoria da economia, a eficiência e a efetividade, contribuindo, ainda, para a melhor alocação de recursos e para a responsabilização pública (OCDE-PUMA, 1997). Na prática, contudo, nem sempre foram feitas ligações entre estes objetivos de alto nível.

\section{Nova Zelândia}

Como já foi indicado, o enfoque das reformas da Nova Zelândia de 1989 foi a obtenção estratégica de resultados pelos ministros de seus ministérios (incluindo resultados de recomendações de política). O objetivo geral era melhorar a economia, a eficiência e a efetividade (pelo menos no que diz respeito aos resultados) das agências públicas. No começo deste período de mudanças, a Nova Zelândia também teve uma forte agenda de corporativização e de privatização, mas em anos recentes as fronteiras gerais do serviço público se estabilizaram. 
Apesar do enfoque nos resultados, as reformas de 1989 também necessitaram que as estimativas (orçamentárias) apresentassem alguma informação sobre os resultados a serem alcançados e as ligações entre os resultados propostos sendo adquiridos, e sua contribuição para estes resultados.

Em 1994, o governo refinou o sistema ao adotar Strategic Result Areas - SRAs (Áreas de Resultado Estratégico) que cobriam, inicialmente, um período de três anos (1994-97), promulgadas posteriormente também para o período de 1997-2000. Estas SRAs cobriam áreas inteiras de política, sem levar em consideração as fronteiras organizacionais, e proporcionaram um mecanismo de coordenação potencial para as atividades ministeriais. Os ministérios foram encorajados a desenvolver suas próprias Key Results Areas - KRAs (Áreas de Resultados-chave) que deveriam ser incorporadas (e ainda são) aos acordos de desempenho entre os ministros e os presidentes executivos. Finalmente, as $S R A s$ foram precedidas por Strategic Priorities and Overarching Goals - SPOGs (Prioridades Estratégicas e Objetivos Superiores) em 1998. De certo modo, as declarações das SRA/ $S P O G$ vieram substituir as declarações de resultado requeridas sob a Lei de 1989 (Controller and Auditor-general, 1999).

\section{Suécia}

Para a Suécia, os principais objetivos da introdução da mensuração do desempenho foram:

- Melhorar a qualidade e a flexibilidade dos serviços públicos;

- Transformar as relações de contabilidade existentes no sentido de um maior enfoque nos resultados; e

- Alcançar substanciais ganhos de eficiência e reduzir o déficit orçamentário.

Este é um contexto mais amplo, (a) da crise fiscal já mencionada anteriormente e (b) de uma necessidade detectada de as agências controlarem mais de perto a responsabilização de suas atividades e desempenhos.

\section{Estados Unidos da América}

Nos Estados Unidos, recentes desenvolvimentos na mensuração do desempenho e em sua prestação de contas têm ocorrido em todos os níveis de governo, desde as agências federais até os ministérios, passando dos governos dos Estados aos governos locais. Muito está sendo reportado sobre estes desenvolvimentos, mas neste estudo estamos focalizando tão somente as mudanças no nível federal, que são principalmente atribuíveis ao GPRA, aprovado pelo Congresso em 1993.

O GPRA foi uma parte importante da agenda do "reinventando o governo" (reinventing government), do governo Clinton/Gore, que centrava-se na idéia do governo "empreendedor". Isto significava uma 
desregulamentação dentro do governo, um enfoque mais claro nos resultados, uma melhor resposta do cliente (incluindo a resposta pelo uso de tecnologias de informação), e melhorias na eficiência. A mensuração do desempenho e sua prestação de contas foram vistas tanto como um condutor de mudança como uma maneira de "reconectar" as agências públicas com o público. Isto também ocorreu dentro de um contexto mais amplo do debate de um "orçamento equilibrado" sobre a redução (e de fato a eliminação) dos déficits do governo e de seus empréstimos.

O objetivo do GPRA era "de transferir o enfoque da tomada de decisões do governo e de sua prestação de contas para longe de uma preocupação com as atividades empreendidas — tais como concessões dispensadas ou inspeções feitas - para um enfoque nos resultados de tais atividades, tais como os ganhos reais em termos de empregabilidade, na segurança, na receptividade, ou na qualidade do programa” ( GAO 2000 - GAO website). Este foi um claro objetivo de transferir a atenção do processo e dos resultados em direção aos impactos.

\section{Resumo}

O ponto de partida para os objetivos gerais dos sistemas de mensuração do desempenho variou enormemente desde um enfoque primário na economia ou na eficiência interna (por exemplo, os primeiros desenvolvimentos na Holanda) ou os fins de resultados/impactos do processo de "produção" do setor público (por exemplo, na Austrália) e políticas/decisões de alocação de recursos (por exemplo, na Nova Zelândia). Também existem diferenças de maior importância entre um enfoque sobre o que poderia ser vagamente chamado de questões "gerenciais" (por exemplo, nos Estados Unidos) ou um enfoque em questões de "responsabilização e prestação de contas" (como no Canadá).

Existe, contudo, uma notável tendência para que a mensuração do desempenho se expanda em sistemas de propósitos múltiplos, cobrindo uma vasta gama de questões gerenciais e de responsabilização. Em alguns casos (por exemplo, a Finlândia e o Canadá), também existe uma tentativa consciente de direcionar-se a abordagens do tipo Balanced Scorecard na gestão de organizações públicas.

\section{O que está sendo medido e que tipo de medidas estão sendo usadas?}

Esta seção procura enfocar com um pouco mais de detalhe algumas mensurações específicas que estão sendo empreendidas e relatadas. A abordagem adotada é similar àquela usada pelo $N A O$ no Reino Unido: insumos, processo, resultados, categorias de impactos, juntamente com a mensuração de eficiência, efetividade e medidas avaliativas. 
O foco da informação sobre o desempenho nos ministérios e nas agências federais australianos é nos recursos utilizados (dentro de uma teoria incremental), nos resultados e nos impactos.

Espera-se das agências:

- Especificar os resultados que elas irão alcançar e para qual política de governo eles contribuem;

- Especificação dos resultados inclui identificar o preço, a qualidade, a quantidade e qualquer outro tipo de atributos-chave;

- Especificação dos impactos inclui proporcionar a informação de desempenho sobre impactos atuais e a contribuição que os resultados obtidos proporcionaram nestes últimos; e

- Fazer uma distinção clara entre os resultados produzidos pelas agências que eles controlam e daquelas que são simplesmente administradas em nome do governo (Barrett, 2000).

As diretrizes sobre informações de desempenho do DOFA estipulam que ambas as informações sobre resultados e impactos devem ser produzidas. Os resultados são claramente definidos, e as agências são orientadas a proporcionar dados sobre itens, tais como: o preço por unidade produzida, quantidade, qualidade, e de contribuição aos impactos. Exige-se que as informações de desempenho sobre os impactos tratem primeiramente da efetividade (Ministério das Finanças e da Administração, 1998; Ministério das Finanças e da Administração, 1999).

\section{Canadá}

O sistema de indicadores e de medidas do desempenho canadense evoluiu consideravelmente desde seu lançamento em 1994. Até 1999, a cobertura das medidas era relativamente abrangente, tanto em termos de aspectos de desempenho (insumos, processo, resultados, impactos, prestação de serviços, eficiência etc.) quanto da cobertura do serviço público federal. Certas preocupações continuam a ser apontadas, tanto pelo Parlamento quanto pelos exames de auditorias do sistema, sobre o escopo e a utilidade da informação proporcionada, mas existem esforços claros no sentido de tratar de tais questões.

Três aspectos são de interesse particular:

1) Uma tentativa de integrar as questões de resultados com a gestão - incluindo a gestão de risco e a questão ética e de valores por meio de uma iniciativa de "controle moderno";

2) Uma prestação de contas mais abrangente - com um forte enfoque na acessibilidade parlamentar e pública; e 
3) Tentativas de estabelecer metas e prestações de contas "intergovernamentais" mais fortes (ligando agências federais, estaduais e locais).

\section{Dinamarca}

As reformas de desempenho na Dinamarca tiveram um enfoque nos "contratos de desempenho", que têm sido vistos como "a iniciativa mais bem-sucedida de gestão pública dos anos 90" (OCDE-PUMA website). Até 1999, foi relatado que cerca de 80 agências estatais e outras entidades tinham contratos de desempenho que, em maior ou menor medida, desciam em cascata no âmbito da organização. Devido à falta de um modelo de contrato de desempenho ditado centralmente, existe uma ampla divergência de interpretações sobre o que significa "desempenho" neste contexto.

A experiência parece demonstrar que, de fato, os contratos de desempenho se focalizaram em mensurações de processo, ou de resultado. Mais recentemente, no final dos anos 90, os ministérios têm sido orientados a desenvolver medidas mais focalizadas no resultado. Também aconteceram iniciativas geradas em torno da qualidade do serviço — o Ministério das Finanças começou a conduzir levantamentos nacionais de satisfação com vários serviços, e estes têm sido usados como termo de comparação e para o desenvolvimento da qualidade dos serviços.

Como parte do orçamento de 2001, o Ministério das Finanças anunciou um corte geral nas dotações orçamentárias de todas as agências estatais, baseado em uma avaliação de que é possível para as agências estatais economizar em suas compras e contratações públicas.

\section{Finlândia}

As crises econômicas e fiscais do início dos anos 90, na Finlândia, resultaram na "perspectiva de que a gestão de desempenho tinha se resumido à produtividade e à economia." (OCDE).

Isto aconteceu apesar da posição formal de que as agências eram encorajadas a desenvolver um conjunto de medidas de desempenho gerais, cobrindo a economia, a eficiência e a efetividade (OCDE-PUMA, 1997). Na busca de corrigir este desequilíbrio em relação à economia e à eficiência, houve tentativas de introdução tanto do modelo da European Foundation for Quality Management (Fundação Européia para a Gestão da Qualidade) quanto do Balanced Scorecard, e também houve iniciativas em relação ao serviço prestado ao cliente e à qualidade. 
Apesar da longevidade da prestação de contas do desempenho (iniciada em 1976), um estudo do orçamento de 1993 mostrou que este "se focalizava em fatores abaixo das estimativas orçamentárias, i.e., indicadores de insumos (volume e custo), com alguns indicadores de resultados, mas com poucos indicadores de impacto." (OCDE-PUMA, 1997).

A ênfase foi direcionada para a eficiência, com a introdução gradual de indicadores nos orçamentos anuais dos ministérios. Em 1997 e em 1998, a ênfase foi posta nos indicadores que proporcionaram um conhecimento profundo do custo total por "unidade de desempenho". Os orçamentos de 1999 tiveram a introdução de indicadores de efetividade, que proporcionaram informação sobre a medida em que as metas da política tinham sido alcançadas.

Mais tarde, a questão da qualidade do serviço também foi levantada e, em resposta às críticas das organizações semi-autônomas (vagamente equivalentes às organizações públicas não ministeriais do Reino Unido), também houve uma crescente ênfase nas questões de transparência e prestação de contas.

Um movimento a mais em direção a um serviço público orientado com base no resultado foi a introdução da gestão de contratos, que começou no nível local, mas que é agora implementada no nível nacional, sempre que possível. A política do governo é de estender este tipo de gestão, com uma maior flexibilidade no pagamento dos gerentes do setor público.

\section{Nova Zelândia}

Como já foi indicado, o enfoque da Nova Zelândia na mensuração de desempenho, como definida pela Lei de 1989, foi nos resultados. Contudo, nos últimos anos houve um movimento crescente no sentido de cobrir os resultados e os impactos (as prioridades-chave dos ministérios ou os objetivos governamentais centrais) e o serviço ao cliente.

Estudos práticos efetuados pelo Office of the Auditor-General $O A G$, demonstraram que o serviço ao cliente e as ligações entre os resultados e os impactos nem sempre foram suficientemente estabelecidos e a cobertura das prioridades-chave dos ministérios por medidas de desempenho de resultados nem sempre tem sido tão abrangente ou firmemente definida como deveria ser. $\mathrm{O}$ grau de orientação central também significa que existe uma tendência a usar uma abordagem "tamanho único" para o desempenho e que falham na distinção entre a responsabilização e prestação de contas públicas e os usos gerenciais das informações de desempenho (Neale e Daken, 2000). 
Cada agência tem que produzir um relatório anual incluindo dados de desempenho, que deveria cobrir insumos, resultados, produtividade e qualidade. Contudo, as auditorias anuais feitas pelo Swedish Nacional Audit Office - SNAO (Gabinete Nacional de Auditoria da Suécia) mostraram que os relatórios tendem, na prática, a se concentrar na carga de trabalho, nas atividades, em medidas quantitativas de produtividade e em material qualitativo e descritivo. Gradualmente uma mudança foi alcançada em direção a um melhor uso de medidas, cobrindo a qualidade do serviço e os impactos. Até 2000, ainda estava sendo concluído que "a documentação que o governo recebe das agências, como uma base para sua reavaliação das atividades, ainda não é plenamente satisfatória." (Atualização do Exame da OCDE 2000 — website da OCDE).

\section{Estados Unidos da América}

A análise feita pelo $G A O$ dos planos de desempenho para o exercício fiscal de 2000, submetidos pelas agências, sugere que enquanto houver um movimento geral no sentido de que a mensuração de desempenho reflita tão somente os objetivos estratégicos, existirão debilidades ( $G A O$, USA, 1999). Particularmente, os planos das agências deram uma imagem "geral" em vez de uma imagem "clara" de desempenho; elas tenderam a sub-reportar o desempenho em áreas "transversais" e também forneceram detalhes insuficientes sobre os planos gerenciais para distribuir recursos e gerenciar os riscos na busca de resultados.

Das 24 agências estudadas, apenas quatro receberam a aprovação do $G A O$ por proporem uma "clara" intenção de desempenho, 14 receberam a classificação de "gerais", enquanto seis permaneceram com a classificação de "limitadas" (vale frisar que nenhuma foi considerada "incerta").

$\mathrm{O} G A O$ e os inspetores-gerais das agências identificaram cerca de 300 "desafios gerenciais e riscos nos programas" específicos, e o GAO analisou se eles haviam sido objeto de tratamento em planos de desempenho. Eles descobriram que cerca de $40 \%$ deveriam ser medidos diretamente, cerca de $18 \%$ indiretamente e $18 \%$ foram cobertos em uma estratégia mais geral de informe. Contudo, cerca de $18 \%$ não eram sequer cobertos pelos planos de desempenho, incluindo um número significativo de riscos de "alto nível".

Esta análise embasada tende, portanto, a mostrar que os planos de desempenho das agências geralmente cobrem, ao mesmo tempo, questões de resultados (impactos) e de métodos (processo e produto), mas não de maneira consistente ou completa, embora a situação esteja melhorando ano após ano. 
Esta questão também foi tratada pela National Partnership for Reinventing Government - NPRG (Parceria Nacional pela Reinvenção do Governo) em um relatório que tenta incentivar o uso de "medidas equilibradas" que "estabelece um conjunto de medidas voltadas para resultados que equilibram" o desempenho de "negócios, clientes e empregados" (NPRG, 1999).

\section{Resumo}

Os pontos principais a incluir no resumo são:

- Da mesma forma que os diversos objetivos gerais dos sistemas de desempenho (Seção 3), as medidas de desempenho detalhadas que foram implementadas são bastante diversas em seu alcance, mas também tendem a expandir sua cobertura.

- Ocorre, freqüentemente, uma separação entre a política oficial sobre que desempenho deveria ser objeto de comunicação e a implementação do quadro geral dentro dos ministérios e agências. Em alguns casos, a despeito de histórias bastante longas de implementação de sistemas de desempenho, esses problemas persistem.

\section{São utilizadas mensurações transversais?}

Um fator que veio à tona durante nossa pesquisa, e que incluímos aqui como uma categoria analisada separadamente, é a questão do "governo integrado"(joined-up-government). Neste contexto, a questão diz respeito a como o desempenho pode ser (ou está sendo) medido em circunstâncias nas quais estão sendo feitas tentativas no sentido de uma melhor coordenação. As experiências, neste caso, são bastante diversas.

\section{Austrália}

Há poucas provas de que a questão das medidas de corte de custos, ou do "governo integrado" ainda seja uma questão de monta nos serviços federais australianos - embora haja algum reconhecimento de que a responsabilização e o desempenho possam ser complicados pela complexidade nas transferências das organizações públicas (ver, por exemplo, Barrett, 2000). No entanto, o Public Service Comissiones (Comissário para o Serviço Público), em seu State of the Service Report - SOSR (Relatório de Serviço do Estado) de 1999-2000, comentou que as agências estão se empenhando cada vez mais em um sistema integrado de gestão de desempenho. "As boas práticas em curso sugerem que as abordagens mais efetivas ao planejamento e a gestão das expectativas de desempenho, no 
serviço público australiano, são aquelas que identificam claramente as expectativas de desempenho e reúnem as pessoas, os processos e os resultados".

A criação do Centrelink em 1997 — uma agência que proporciona um acesso de guichê único para uma ampla variedade de serviços do governo - é um forte exemplo de tratamento do problema da coordenação de prestação de certos tipos de serviços públicos over the counter. ${ }^{1}$ Contudo, esta iniciativa não parece estar ligada a qualquer consideração mais ampla de políticas de "integração" de organizações e serviços (ver a atualização do website da OCDE-PUMA, Austrália, 1998).

Reconhece-se, cada vez mais, que um número de agências pode contribuir para um resultado particular. A questão de determinar o desempenho e a responsabilização entre as agências nestas situações ainda está para ser plenamente descrita.

\section{Canadá}

A política de revisão de programas, introduzida em 1994, proporcionou medidas para gerenciar o "uso em comum" dos recursos para a busca de metas coletivas naqueles casos em que os ganhos em eficiência estimulam uma melhor colaboração.

O relatório anual do Presidente da $T B S$, agora chamado de Managing for Results (Gerenciando por Resultados), proporciona um acesso aos resultados e à informação de desempenho em que mais de um ministério estão trabalhando juntos. $\mathrm{O}$ governo também está explorando como o "pacote de outono" pode ser usado para melhor "usar em comum" os planos ministeriais durante as consultas e as revisões subsequientes.

O Managing for Results 1999 contém vários exemplos de metas de desempenho comuns aos diferentes níveis de governo, tanto nos níveis interministeriais como nos "intergovernamentais". Por exemplo, a iniciativa dos Grandes Lagos, em 2000, reúne a Environment Canada, seis outros ministérios federais e quatro secretarias estaduais de Ontário, no estabelecimento de 50 metas de desempenho para melhoramentos do meio ambiente e da saúde.

\section{Dinamarca}

As agências na Dinamarca são ativamente encorajadas a trabalhar juntas. Considera-se como um pré-requisito-chave para o sucesso contínuo da estratégia de desempenho dinamarquesa o desenvolvimento de ferramentas que apóiem os esforços dos administradores em proporcionar serviços de maneira mais efetiva em relação ao custo, incluindo-se nestas ferramentas o desenvolvimento de trabalhos mais coordenados. 
No final de 1999, o Ministério das Finanças iniciou o Effective Public Processes (Projeto de Processos Públicos Efetivos) para proporcionar aos administradores as ferramentas para a reengenharia de processos e para facilitar a troca de experiências e de práticas eficientes.

Contudo, não conseguimos encontrar nenhuma evidência de mecanismos de mensuração de desempenho em "conjunto" deste tipo.

\section{Finlândia}

Um grupo de trabalho sobre avaliação (Ministério das Finanças) relatou que a avaliação dentro da administração estatal deveria ser coordenada. O grupo expressou a visão de que a falta de coordenação é considerada como um problema, particularmente no caso de programas interadmi nistrativos dentro da área de política social. O grupo comentou que "é importante que o princípio de comparação de desenvolvimento seja aplicado entre e dentro das respectivas áreas administrativas, como um método estratégico relacionado tanto ao desempenho quanto aos processos".

Novamente, como no caso da Dinamarca, não conseguimos encontrar qualquer evidência de mensuração de desempenho transversal.

\section{Holanda}

Parece que não existem medidas específicas. Alguns ministérios, especialmente o Ministério das Finanças e o Ministério do Interior, procuram particularmente aspectos gerais da administração pública, tais como a efetividade e os recursos humanos. Contudo, suas habilidades para impor medidas a outros ministérios são limitadas e dependem da persuasão. Acredita-se que uma melhor integração se transformará em objetivo importante num futuro próximo.

Alguns programas de mensuração de desempenho, tanto no nível central quanto no nível local, contêm elementos de resultados do uso de termos de comparação (benchmarking).

\section{Nova Zelândia}

Como já foi ressaltado anteriormente, a introdução de $S R A s$, em 1994, e depois de SPOGs, em 1998, proporcionaram um mecanismo, muito embora em um nível muito alto, de declaração de objetivos de desempenho. A prestação de contas específicas comparadas com metas "transversais" foi experimentada nas iniciativas do programa Strengthening the Families (Fortalecimento de Famílias final dos anos 90), onde adotouse um método de prestações de contas comparadas às $S P O G s$ (esta iniciativa está agora em compasso de espera), e em 2000 adotou-se a iniciativa 
de "preencher as lacunas", embora a maior parte dos relatórios ainda esteja restrita às fronteiras ministeriais e a seus resultados (Neale e Daken, 2000).

\section{Suécia}

Parece não haver evidencia de que a questão de mensurações "transversais" ainda tenha sido abordada na Suécia. Contudo, a questão de uma melhor coordenação de serviços e de políticas foi levantada em decorrência do movimento de concentração — reestruturação de serviços públicos (especialmente as reorganizações e as fusões de agências) - e o desenvolvimento de um enfoque na colaboração.

\section{Estados Unidos da América}

De acordo com a análise do $G A O$, a mensuração de questões transversais está melhorando, mas ainda resta muito a ser feito. $\mathrm{Na}$ maioria dos casos, as agências têm relacionado, em seus planos de desempenho da GPRA, o problema da identificação de questões transversais e a divisão de responsabilidades, e começaram a adotar estratégias para relacioná-las.

A Social Security Agency - SSA (Agência de Seguridade Social) e a Veterans' Administration - VA (Administração dos Veteranos) são especificamente mencionadas pelo desenvolvimento de estratégias sobre questões transversais e algumas medidas de desempenho compartilhadas ou são apresentadas como relacionadas às melhorias de coordenação. O Department of Health and Human Services (Ministério da Saúde e dos Serviços Humanos) foi recomendado pelo desenvolvimento de metas de desempenho interligadas — por exemplo, metas relacionadas à redução do uso do tabaco para os Centers for Disease Control and Prevention (Centros de Controle de Doenças e de Prevenção) e a Food and Drug Administration - FDA (Agência de Alimentos e Drogas).

Por outro lado, o Departament of Defense - DOD (Departamento de Defesa) é especificamente mencionado por falhar na identificação de questões transversais (por exemplo sobre o terrorismo).

O GAO conclui que "poucas agências conseguiram ultrapassar a identificação de esforços e de estratégias transversais para incluir em seus planos metas de desempenho complementares".

\section{Resumo}

Embora exista claramente um reconhecimento em todos os países estudados de que as políticas "transversais", de coordenação e de "uso em comum", de organizações e de serviços constituem uma importante 
questão, a maneira como isto está sendo tratado varia consideravelmente.

Na maioria dos casos, os países a estão tratando, inicialmente, como uma questão de avaliação gerencial ou orçamentária, e ainda não no nível de mensuração de desempenho transversal. O Canadá e, em menor medida, os Estados Unidos da América parecem ser as exceções, com tentativas explícitas de criar sistemas de desempenho transversais de maior uso em comum (em ambos os casos ativamente encorajados por suas entidades superiores de auditoria).

\section{Como é garantida a qualidade da informação?}

Com o crescimento da importância da informação de desempenho dentro do governo, é obviamente crucial que a informação proporcionada seja de qualidade, confiabilidade e validade suficientes para ser aceitável por todos os interessados. Nesta seção, iremos explorar os acordos para garantir a qualidade da informação de desempenho.

\section{Austrália}

O Australian National Audit Office - ANAO (Gabinete Nacional de Auditoria Australiano) leva a cabo auditorias de desempenho cobrindo a economia, a eficiência e a efetividade das organizações do setor público, examinando o uso de recursos, os sistemas de informação, a prestação de resultados e seus impactos, incluindo indicadores de desempenho, monitoramento dos sistemas e a observância dos aspectos éticos e legais. Contudo, como no Reino Unido, estas auditorias de desempenho são levadas a cabo de acordo com a descrição do auditor-geral, e não há exigência geral para uma auditoria e validação das informações sobre o desempenho.

O papel do Comitê de Auditoria tem tido um crescimento contínuo no DOFA, desde 1997. O Comitê de Auditoria está focalizado na garantia de um governo corporativo, incluindo o monitoramento da gestão de risco dentro do ministério. Ele tem o objetivo de promover ativamente a melhoria do controle e do desempenho em todo o ministério.

As agências também têm que ter um comitê de auditoria, responsável pela auditoria interna da informação de desempenho. O ANAO levou a cabo uma auditoria destes acordos de auditoria interna em 1997, para verificar se as agências poderiam responder às novas exigências financeiras e de prestação de contas de desempenho. Eles concluíram que a maioria das agências conseguiam realmente responder, mas que apenas uma minoria estava operando plenamente ou perto da "melhor prática possível" e que havia, então, um problema geral potencial, decorrente da falta de 
representação externa nos comitês de auditoria $(A N A O, 1997)$. A pesquisa

sublinhou que cerca de um quarto das 137 agências examinadas não tinham um comitê de auditoria e que várias também não tinham uma função interna de auditoria.

\section{Canadá}

Os ministérios do governo têm como finalidade adotar os princípios de administração de qualidade como parte de sua estratégia geral, e de conduzir auditorias internas e avaliações das políticas e dos programas centrais, de acordo com os padrões estabelecidos.

Toda a informação de desempenho apresentada ao Parlamento como parte dos novos sistemas orçamentários (ver anteriormente) está sujeita a uma auditoria pelo $O A G$. As principais questões levantadas pelo $O A G$ em anos sucessivos têm sido sobre a qualidade dos dados financeiros, a falta de enfoque nos resultados, nos problemas de cobertura dos dados de desempenho e, finalmente, o problema de informação de desempenho de novas formas de prestação de serviços (i.e., entidades delegadas, setor voluntário, serviços terceirizados etc.).

\section{Dinamarca}

O Danish Office of Auditor-General - DOAG (Gabinete do Auditor-Geral Dinamarquês) proporciona ao Comitê de Contabilidade Pública dinamarquês auditorias regulares de informação de desempenho, proporcionadas pelos ministérios e as agências (o DOAG tornou-se uma entidade parlamentar em 1991). O DOAG também leva a cabo auditorias de desempenho específicas. As agências têm, em sua maioria, evitado introduzir auditorias internas, e onde elas o fizeram, essas são principalmente restritas à auditoria financeira. Por outro lado, algumas das principais agências são auditadas por auditores internos.

\section{Finlândia}

A Finlândia é praticamente o único país a ter duas entidades de auditoria nacionais: uma ligada ao governo, o State Audit Office - SAO (Escritório de Auditoria do Estado), e uma ligada ao Parlamento, o Office of Parliamentary State Auditors - OPSA (Escritório de Auditores Estatais do Parlamento), os auditores sendo membros do parlamento. O SAO é, de longe, a maior das duas entidades, e leva a cabo tanto a auditoria de dados de desempenho de rotina, proporcionada pelas agências e pelos ministérios (como parte de sua auditoria de transferências financeiras), quanto as auditorias episódicas de desempenho. 
Alguns ministérios têm adotado avaliações por entidades independentes em suas principais funções. As avaliações de programas são iniciadas em uma base ad hoc por um grande número de organizações, incluindo o OPSA.

\section{Holanda}

O Algemene Rekenkamer (Tribunal Holandês de Auditoria) compreende três membros nomeados pela Rainha, mediante recomendação do Parlamento, e tem por volta de 300 funcionários em sua equipe. $\mathrm{O}$ tribunal tem um mandato explícito para auditar a eficiência e a efetividade, incluindo revisões de sistemas de mensuração de desempenho, sistemas adminis trativos, e revisões da efetividade dos programas. Os dados de desempenho produzidos em decorrência da Lei de Responsabilização do Governo não estão sujeitos a uma auditoria explícita separada pelo tribunal, mas este pode chamar a atenção para inexatidões onde julgar conveniente.

O Ministério das Finanças também tem um Central Auditory Departament - CAD (Departamento Central (interno) de Auditoria), e cada um dos ministérios tem sua própria função de auditoria interna; contudo, enquanto as auditorias internas dos ministérios levam em consideração os dados de desempenho, o $C A D$ não o faz.

\section{Nova Zelândia}

O $O A G$ é responsável pela auditoria da informação de desempenho. Especificamente, as auditorias de relatórios anuais incluem a "justeza da prestação de contas do desempenho do serviço" e das "questões adicionais específicas em relação ao desempenho das organizações, baseadas na avalia ção dos riscos específicos na organização" $(O A G, 2000)$. O $O A G$ também pode levar a cabo auditorias específicas da informação de desempenho.

O $O A G$ compara suas avaliações de sistemas de desempenho ministeriais sob duas categorias: Service Performance Information Systems - SPIS (Sistemas de Informação de Desempenho dos Serviços) e Service Performance Management Central Environments - SPMCE (Ambiente de Controle da Gestão de Desempenho dos Serviços). Para a gestão de 1998-99, o gabinete descobriu que 17\% dos relatórios apresentavam "excelentes" padrões para os SPIS, e 33\% para os SPMCE, com respectivamente $52 \%$ e $43 \%$ "bom", e $31 \%$ e $24 \%$ "satisfatório". O $O A G$ também comparou estes resultados com o ano anterior, e concluiu que, enquanto $75 \%$ permaneciam estáticos, $20 \%$ apresentaram melhorias e $5 \%$ apresentaram quedas. O $O A G$ declara que isto comprova uma melhoria marcante em comparação com o progresso de anos anteriores (Controller and Auditor-General, 1999). 
O Reksrevisionsverket $-R R V$ (Gabinete de Auditoria Nacional Sueco) desenvolveu um forte sistema de auditoria de desempenho. O $R R V$ também é responsável pela auditoria de qualquer informação de desempenho que uma agência possa vir a publicar em seus relatórios anuais (a Suécia conta com duas entidades de auditoria - o $R R V$, que é uma entidade governamental, é a maior, e também há uma pequena entidade de auditoria parlamentar).

A Suécia vê seu sistema de auditoria como suficientemente avançado para formar a base de um programa de treinamento e de monitoramento desenvolvido por sua instituição superior de auditoria para Estados em desenvolvimento e em transição $(R R V, 1999)$.

\section{Estados Unidos da América}

A análise do GAO dos planos de desempenho para o ano 2000 concluiu que havia uma confiança limitada de que os dados de desempenho das agências fossem confiáveis. Eles classificaram os planos das agências como tendo proporcionado:

- "plena confiança" - verificado em nenhum plano;

- "confiança geral" - verificado em apenas quatro planos;

- "confiança limitada" - que se aplicava a 20 planos; e

- "sem confiança" — não se aplicava a nenhum plano.

O GAO declara que "poucas agências proporcionam discussões explícitas de como elas têm a intenção de verificar e validar os dados de desempenho." O GAO também ressalta que este problema geral está ligado a "limitações persistentes na disponibilidade de dados de qualidade financeira."

\section{Quem pode ser responsabilizado pelo desempenho?}

A questão de responsabilização pelo desempenho é uma questão complexa. Esta seção discute os vários arranjos em cada um de nossos países-tema.

\section{Austrália}

Os ministros, as secretarias dos ministérios e os presidentes executivos das agências têm todos alguma responsabilidade pelo desempenho (sendo que todos os dirigentes recebem remuneração relacionada ao desempenho), por mais que os ministérios e as agências, como um 
todo, sejam claramente responsáveis pela gestão de desempenho (Department of Finance and Administration, 1998 e 1999).

Os ministérios do governo compartilham com os ministros um elemento de responsabilização pelo alcance dos resultados. Enquanto que os servidores públicos não são responsabilizados, sozinhos, quanto a se os resultados são ou não alcançados, espera-se deles que demonstrem que todos os resultados que eles proporcionam contribuam para um resultado maior. Por exemplo, o DOFA não é responsável por seu impacto sobre as finanças governamentais sustentáveis - se os governos querem tomar decisões que impedem a sustentabilidade a longo prazo, ou se as condições econômicas internacionais tornam a sustentabilidade do alcance financeiro mais difícil do que o planejado, isto não é tratado como uma responsabilidade do grupo orçamentário. Contudo, o DOFA é responsável pela demonstração de que todos os seus resultados, por exemplo os pareceres orçamentários, a gestão orçamentária etc., ajudam a alcançar o objetivo de finanças governamentais sustentáveis.

\section{Canadá}

Como já foi discutido anteriormente, em termos de responsabilidade pela projeção de metas de desempenho, o sistema canadense divide de forma efetiva a responsabilidade entre o governo (basicamente o TBS e o Ministério das Finanças), o Parlamento (incluindo os comitês existentes) e os ministérios ou as agências. Em termos de gestão de desempenho, a responsabilidade claramente cabe aos ministérios e às agências. Para a prestação de contas de desempenho, a responsabilidade também é dividida entre o governo (relatório anual dos Presidentes dos TBS ao Parlamento) e os ministérios ou agências.

\section{Dinamarca}

A estrutura do sistema ministerial dinamarquês é concebida de tal forma que cada ministério consiste de um departamento e de uma ou mais agências subordinadas. $O$ ministro é formalmente, tanto legal quanto politicamente, responsável pelo desempenho do departamento e de todas as suas agências subordinadas.

\section{Finlândia}

O modelo finlandês de contratos de desempenho pode ser caracterizado como um modelo menos formal de quasi contract, no qual a responsabilidade é em certa medida dividida entre os contratantes. A idéia era de criar uma nova cultura de direção que motivasse os ministérios e as 
agências a encontrar sua própria maneira de fazer as coisas. Os contratos entre os ministérios e as agências não são estatutários, e o termo "contrato" refere-se mais a um acordo mutuamente negociado do que a um contrato com uma base legal estrita.

\section{Holanda}

Cada ministério é responsável pela qualidade da gestão pública e pelo desempenho em sua área política. As entidades autônomas (semelhantes aos organismos públicos não departamentais britânicos ) e as agências, obviamente, podem ser tidos como responsáveis por seus desempenhos individuais.

\section{Nova Zelândia}

Os ministérios são tidos como responsáveis por seu próprio desempenho por meio de seu sistema de contratos de desempenho e de seu sistema de prestação de contas entre os ministros e os presidentes executivos. Os ministérios e os ministros ambos são chamados a responsabilizar-se diante do Parlamento pelos exames de estimativas (ex ante) e das revisões financeiras (ex post) conduzidas por comitês selecionados, assim como a ministerial accountability, averiguada pelo debate no Parlamento.

\section{Suécia}

O sistema de agências sueco estabelece que as próprias agências são responsáveis pelo desempenho.

\section{Estados Unidos da América}

Sob o sistema federal dos Estados Unidos, as agências devem prestar contas formalmente ao Poder Executivo, com uma "revisão" pelo Congresso. Contudo, geralmente são as próprias agências que são vistas como responsáveis por seu próprio desempenho. $\mathrm{O}$ ainda relativamente novo sistema da GPRA implica em um tipo de acordo quase contratual, ao ligar claramente a alocação de recursos pelo processo de dotações orçamentárias do Executivo e do Congresso às metas de desempenho, e as agências têm como responsabilidade seu desempenho efetivo. No entanto, dada a relativa autonomia histórica da maioria das agências americanas, elas são geralmente vistas como independentemente responsáveis por seu desempenho.

\section{Resumo}

A responsabilização (accountability) é complexa. Geralmente os políticos — na forma de ministros (ou no caso americano, os indicados 
políticos pelo presidente) — são tidos como responsáveis pela projeção de padrões de desempenho para os ministérios e as agências, enquanto que os funcionários permanentes, encarregados de dirigir os ministérios ou as agências, são responsabilizados pela implementação do desempenho.

Contudo, estas divisões não são claramente estabelecidas qualquer que seja a posição formal, o grau real de responsabilidade detido pelos políticos ou pelos gerentes é determinado pelos costumes e a cultura locais, às vezes variando até mesmo dentro de países entre áreas de política diferentes (como é de fato o caso do Reino Unido). Também as questões, como por exemplo, se as metas de desempenho para os resultados almejados são realistas, considerando-se o nível de recursos alocados, podem tornar-se bastante complexas e muito rapidamente tornarem-se questões litigiosas.

\section{Como o desempenho é divulgado publicamente?}

As maneiras pelas quais é feita a prestação de contas pública podem ter um impacto significativo sobre a dinâmica do sistema de desempenho. Conforme já indicado, a prestação de contas sobre o desempenho para fins de gerenciamento e de responsabilização pode ter exigências bastante diferentes (Neale e Daken, 2000). A presente seção examina as várias abordagens à prestação de contas sobre dados de desempenho.

\section{Austrália}

A prestação de contas sobre o desempenho é feita por meio de relatórios anuais que as agências apresentam ao Parlamento. As medidas e indicadores são desenvolvidos juntamente com o DOFA e mediante sua assessoria, e segundo suas diretrizes, emitidas sob a forma de princípios de informação sobre desempenho. As agências continuam aperfeiçoando suas informações sobre desempenho para assegurar que elas proporcionem uma indicação prática e precisa de seu trabalho.

Ademais, anualmente a Public Service and Merit Protection Commission (Comissão do Serviço Público e da Proteção do Mérito) emite um relatório sobre o State of the Public Service (Estado do Serviço Público), e o DOFA emite anualmente estratos financeiros consolidados para exame pelo público.

$\mathrm{O}$ auditor-geral e os comitês parlamentares relevantes (Comitê Conjunto Sobre Contas Públicas e Auditoria e o Comitê de Finanças e Administração Pública do Senado) têm feito críticas no sentido de que:

- Os reletórios sobre o Estado do Serviço Público têm um nível demasiado elevado de generalidade para serem úteis; 
- Os dados agregados relativos à totalidade do desempenho do governo não são coletados conjuntamente e publicados;

- Os dados sobre tendências em desempenho não são apresentados adequadamente (Barrett, 2000; Joint Committee of Public Accounts and Audit, 2000; Senate Finance and Public Administration Legislation Committee, 2000).

Os críticos concordaram quanto a que levará tempo para que os novos arranjos "se acomodem", mas também sugeriram que alguns pontos fracos eram inerentes ao novo sistema, tal como atualmente concebido, e que deveriam ser objeto de tratamento (por exemplo, a junção de algumas despesas; prestações de contas anuais únicas; possíveis confusões inerentes à contabilidade incremental etc.).

\section{Canadá}

Até 1995, o primeiro Relatório Anual dos Presidentes dos TBS era apresentado ao Parlamento dentro da revisão de programas e desempenho.

Até 1996, 30 ministérios e agências federais prestaram compromissos-chave sobre resultados, e esses foram objeto de prestação de contas no Getting Government Right: Improving Results, Measurement and Accountability (Relatório dos Presidentes dos TBS ao Parlamento).

Até 1999, o Relatório dos Presidentes dos TBS - Managing for Results 1999 - foi dividido em dois volumes: o primeiro que cobria uma gama de questões gerais sobre os sistemas de prestação de contas sobre desempenho e seu desenvolvimento, e o segundo, que cobria relatórios de desempenho pormenorizados de ministérios e agências.

Também foi criado um banco de dados online: o Results and Performance Database (Banco de Dados sobre Resultados e Desempenho).

\section{Dinamarca}

As informações sobre desempenho geralmente estão disponíveis para o público, inclusive os contratos de desempenho e os resultadoschave. Os (novos) relatórios anuais são documentos centrais que exigem uma seção "Resultados" que cubra atividades e resultados-chave a serem publicados.

\section{Finlândia}

Os arranjos para a publicação de dados sobre desempenho na Finlândia são quase idênticos aos da Dinamarca, incluindo tanto os dados sobre desempenho em relatórios anuais quanto com relação a contratos de desempenho. 
As informações sobre desempenho estão contidas em demonstrativos financeiros e relatórios anuais, mas nem sempre são disponibilizadas para o público. É exigido dos ministros que proporcionem dados anuais sobre desempenho em suas estimativas orçamentárias, a fim de informar o processo orçamentário, mas, igualmente, isso não é necessariamente publicado. Os contratos de desempenho contêm informações sobre desempenho, mas geralmente não estão disponíveis para o público.

O Public Services Quality Monitoring System (Sistema de Monitoramento da Qualidade do Serviço Público) avalia a qualidade e a eficiência dos governos locais. São publicadas tabelas que proporcionam comparações de desempenho.

\section{Nova Zelândia}

Na Nova Zelândia, a prestação de contas sobre desempenho é feita publicamente, por ministério, em comparação com as estimativas e seu DFR. Os contratos de desempenho ocorrem exclusivamente no âmbito do Executivo - comitês seletos muitas vezes convocam a realização de acordos de compras como parte de seu exame, mas seu uso formal fica restrito aos ministérios e seus ministros.

\section{Suécia}

As agências suecas devem publicar informações sobre desempenho em seus relatórios anuais. No entanto, conforme já se disse, a forte autonomia constitucional das agências suecas faz com que, na prática, elas próprias escolham sobre o que prestar contas (além das informações financeiras padrão).

\section{Estados Unidos da América}

Cada agência presta contas individualmente ao público sobre sua própria performance, por meio de seu sistema de desempenho e prestação de contas anual. O GAO comenta relatórios de desempenho e planos de desempenho individuais, mas somente agrega a análise dos planos e não dos relatórios.

\section{Resumo}

Atualmente, a maior parte dos países publica uma grande quantidade de dados sobre desempenho. As exceções identificadas no presente levantamento são a Suécia, onde tem ocorrido alguma reticência 
entre as agências quanto à publicação de todas as informações sobre desempenho, e a Holanda, onde há uma tradição no sentido da não publicação de todas as informações sobre desempenho.

A questão, para a maioria dos países, passou a ser a do alcance da prestação de contas sobre desempenho (quanto cobrir) e a questão correlata da acessibilidade e da abrangência dos dados sobre desempenho que são publicados. O Canadá se destaca como pioneiro em matéria de práticas inovadoras de publicar informações na Internet.

\section{Quais são as principais evoluções em curso?}

Esta seção simplesmente relata ou comenta as evoluções recentes ou propostas ligadas ao desempenho, que ainda não tenham sido mencionadas ou plenamente cobertas em outras seções deste estudo.

\section{Austrália}

Em conseqüência de regulamentos apresentados ao Parlamento em março de 1998, a Comissão Australiana para o Serviço Público deve apresentar ao Parlamento um relatório anual sobre a situação do Australian Public Service - APS (Serviço Público Australiano). O primeiro relatório APS foi apresentado ao Parlamento em dezembro de 1998, e se concentrou na implementação da declaração dos valores do serviço público australiano.

O Internal Audit Alliance Contract (Contrato Interno de Aliança de Auditoria) foi firmado pelo DOFA e um parceiro, em 2 de novembro de 2000, para a prestação de toda a gama de serviços de auditoria e afins durante os próximos três anos. Isto substitui o arranjo anterior, expirado em 20 de outubro de 2000. Desde essa revisão (fim de 1999) foi criada uma nova divisão no DOFA, a Risk Management Coordination Branch (Divisão de Coordenação do Gerenciamento de Risco), com a finalidade de lidar especificamente com toda a gama de questões de gerenciamento de risco no nível ministerial.

O auditor-geral tem advogado, fortemente, uma integração da "conformidade e do desempenho" aos sistemas de desempenho, que se embasem nos valores tradicionais do setor público (Barrett, 2000).

\section{Canadá}

Há algumas evoluções ligadas ao desempenho que ainda não foram mencionadas, entre elas:

- Agency Review (1994): uma revisão de todos os conselhos federais, agências, comissões e órgãos consultivos federais, que resultou 
em decisões no sentido de eliminar organizações ultrapassadas e de enxugar outras.

- Getting Government Right (1996): modernizar programas e serviços federais a fim de atender às necessidades dos canadenses, tanto como cidadãos quanto como clientes, com o objetivo de:

1) Esclarecer os papéis e responsabilidades federais, a fim de fazer com que a federação trabalhe melhor e reduza onerosas justaposições e duplicações.

2) Assegurar que os recursos sejam dedicados às mais altas prioridades, para que o Canadá esteja bem posicionado para enfrentar os desafios econômicos e sociais do século XXI.

3) Responder à demanda do público por um governo melhor e mais acessível, por meio de um envolvimento melhor dos clientes na tomada de decisões e do uso de ferramentas de prestação de serviços modernas e práticas.

4) Conseguir tornar o governo mais barato, mediante a redução das pressões de déficit e da dívida, e permitir que o governo gerencie eficazmente questões que são importantes para os canadenses.

- Performance Management Program (Programa de Gestão de Desempenho): implementado pelo governo federal em $1 \stackrel{0}{\mathrm{o}}$ de abril de 1999, com o objetivo de incentivar a excelência no desempenho, por meio de reconhecimento e recompensa pela consecução de resultados ligados a planos de negócios e/ou prioridades empresariais e demonstração das competências de liderança, dos valores e da ética do serviço público. O programa também proporciona um quadro geral dentro do qual se pode aplicar uma abordagem eqüitativa da gestão do desempenho dos executivos federais.

- Canadian Comprehensive Audit Foundation Public Performance Reporting Program (CCFA): em estreita cooperação com o governo, o CCFA lançou o Public Performance Reporting Program (Programa de Prestação de Contas ao Público sobre Desempenho Plurianual), que consiste em um programa de pesquisa com o objetivo de dar aos governos e a outras instituições do setor público, informações compartilhadas sobre desenvolvimento de capacidades e de como obter pleno retorno de seus investimentos em responsabilização.

\section{Dinamarca}

Uma nova e importante iniciativa no âmbito da reforma da gestão pública - o Service and Welfare Project (Projeto de Serviço e Bemestar) - é o resultado da cooperação entre o governo dinamarquês, a Association of Country Councils (Associação de Conselhos de Condados) e a Association of Local Municipalities (Associação de 
Municípios). A finalidade geral do projeto é criar um quadro geral para o aprendizado e a reforma do setor público, e promover o debate sobre os futuros desafios do setor. $O$ projeto tem mais três finalidades secundárias:

- facilitar experiências e o compartilhamento de conhecimentos sobre gerenciamento, organização e relações com os cidadãos dentro do setor público;

- criar um quadro geral para as reformas do setor público; e

- promover o debate público sobre o futuro da sociedade e do bemestar em geral, inclusive sobre questões relativas ao gerenciamento no setor público.

Obviamente, as informações sobre resultados (tanto de avaliação quanto de desempenho) poderiam fazer parte substantiva dessa iniciativa e poder-se-ia esperar que essas informações aumentassem rapidamente em alcance e profundidade.

Outras iniciativas têm algumas dimensões de "desempenho", por exemplo:

- Um fórum para funcionários públicos de alto nível: criado pelo Ministério das Finanças no final de 1999, a fim de compartilhar conhecimentos, facilitar a coordenação e aumentar o diálogo entre os ministérios. $\mathrm{O}$ fórum consiste de aproximadamente 150 funcionários públicos de alto nível que se reúnem trimestralmente com agendas estabelecidas por um grupo diretor.

- Relatórios anuais (obrigatórios): introduzidos para ministérios e agências, em 1997, e que incorporam resultados de desempenho às contas finais.

- Um novo sistema informatizado para a gestão dos recursos financeiros (Navision Stat): em 1999, o Ministério das Finanças, a Agência para a Gestão Financeira e Assuntos Administrativos introduziram um novo sistema informatizado para a gestão financeira em instituições e agências estatais.

- Um projeto para Processos Públicos Efetivos: iniciado pelo Ministério das Finanças no final de 1999 tem a finalidade de proporcionar, aos gerentes públicos e profissionais, ferramentas para realizar projetos de reengenharia de processos internos e facilitar o intercâmbio transversal de experiências e de práticas eficientes.

- O Prêmio de Qualidade para o Setor Público: criado em 1997, esse prêmio é dado com base em uma avaliação dos candidatos baseada no Modelo de Excelência Empresarial. A finalidade do prêmio é proporcionar às instituições públicas um modelo bem testado para a promoção da qualidade.

- O Centro para o Desenvolvimento de Recursos Humanos e da Gestão de Qualidade: criado em 2000, o centro irá promover e facilitar o desenvolvimento dos recursos humanos e da gestão de qualidade no governo central, por meio da coordenação de atividades existentes, da 
prestação de assessoria a instituições do governo e sindicatos de trabalhadores e da prestação de serviços, entre outros, ao Comitê de Avaliação do Prêmio de Qualidade de Setor Público.

- Declaração de informação aos usuários: desde 1995, é exigida dos municípios, de dois em dois anos, a prestação de contas aos residentes da área local quanto aos conteúdos e ao alcance dos principais serviços públicos a eles prestados ou que se lhes pretende prestar. É exigido que a declaração inclua informações sobre as metas que o conselho municipal tiver identificado para desenvolvimento nas respectivas áreas.

- Gerenciamento de contratos: o gerenciamento do desempenho por meio de contratos de desempenho foi, provavelmente, a iniciativa mais bem-sucedida de gerenciamento público dos anos 90. Em 1999, aproximadamente 80 agências e instituições estatais tinham firmado contratos de desempenho.

- Satisfação dos usuários: o Ministério das Finanças realiza, regularmente (normalmente a cada dois anos), levantamentos de abrangência nacional sobre a satisfação dos usuários e outras questões ligadas ao governo - relações com os cidadãos. Esses estudos são usados como termos de comparação entre áreas do setor público e como ponto de referência em levantamentos locais.

\section{Finlândia}

Em abril de 1998, o governo da Finlândia emitiu uma resolução sobre boa governança, serviço de alta qualidade e uma sociedade civil responsável. As principais áreas de reforma são: continuar as reformas do governo central; melhorar a qualidade dos serviços públicos, e questões de gestão da informação e da sociedade da informação. As eleições de 1999 levaram à formação de um novo governo, composto dos mesmos cinco partidos que compunham o governo anterior, tendo havido, portanto, poucas mudanças nas orientações da reforma. Uma nova constituição entrou em vigor em 1o de março de 2000.

Outras iniciativas específicas, com uma dimensão de desempenho, incluem:

- New Act on Openness of Government Activities (A Lei sobre Transparência das Atividades do Governo de 1999): essa lei implementa o direito de acesso a informações contidas em documentos oficiais no domínio público.

- National Quality Initiative 2000-2001 (A Iniciativa Nacional de Qualidade 2000-2001: este é um projeto de dois anos, lançado pelo Ministério das Finanças, com o objetivo de aumentar o uso do Modelo de Excelência $(E F Q M)$ e das Cartas de Serviço entre as organizações do 
setor público. Há 30 organizações participando da iniciativa, representando todos os níveis do setor público.

- O fórum do Balanced Score Card: o Ministério das Finanças começou o projeto no final de 1999, desafiando as autoridades e as organizações do setor público a participar do fórum do Balanced Score Card para discutir e aprender a partir dos sistemas de gerenciamento estratégico baseados no $B S C$. O objetivo final do projeto é melhorar os sistemas de gerenciamento estratégico do setor público. Vinte e cinco organizações se candidataram ao fórum.

\section{Holanda}

Os ministérios desenvolveram ou estão desenvolvendo planos de ação que estabelecem a criação e o uso de indicadores. A prestação de informações para fins de gerenciamento interno é considerada da maior importância.

Um documento de políticas de governo - Back to the Future (De volta para o Futuro 1995 ) — sobre a prestação de informações, descreve como a prestação de informações e as tecnologias correlatas podem melhorar a acessibilidade e a transparência do governo para com o público. Com base nesse documento, foram desenvolvidos projetos piloto para a criação de centros integrados de informações governamentais. Esses projetos piloto envolveram cooperação entre os governos locais e o governo nacional.

\section{Nova Zelândia}

As principais evoluções parecem ocorrer na área das relações entre as exigências legais para a prestação de contas sobre resultados e as exigências não legais relativas à prestação de contas sobre o impacto (e outras), nas quais há interesse crescente. Tal como em outras jurisdições, há pressões no sentido de uma melhor especificação das metas de desempenho e dos objetivos estratégicos; de uma melhor prestação de contas quanto ao gerenciamento de risco; e de prestação de contas sobre as atividades transversais.

A State Services Commission (Comissão dos Serviços do Estado) empreendeu uma revisão muito abrangente dos arranjos relativos à responsabilização, que inclui o exame de problemas levantados quanto a aspectos de cumprimento de determinações relativas ao desempenho, ex ante, e de custos ligados ao cumprimento dessas determinações (Relatório Schick).

Planeja-se uma nova abordagem para a responsabilização no nível ministerial e para a avaliação de desempenho - a iniciativa sobre Capability, Accountability and Performance - CAP (Capacidade, 
Responsabilização e Desempenho). Isso envolve novos documentos de planejamento estratégico para que os ministérios cubram um alinhamento mais estreito de recursos na direção de objetivos estratégicos, que são assinados tanto pelos ministros quanto pelos dirigentes executivos. Em ministérios piloto, a atual "avaliação ministerial de desempenho" será substituída por um sistema que incluirá a análise retrospectiva do desempenho e a análise prospectiva de capacidade. O modelo EFQM também será usado em alguns ministérios. Surgiu também um novo papel para a Comissão dos Serviços do Estado com relação às agências centrais, que funciona como um órgão consultivo para questões de "propriedade".

A Comissão dos Serviços do Estado também emitiu nova orientação sobre a responsabilização e as responsabilidades dos dirigentes públicos.

\section{Suécia}

A autonomia de base constitucional das agências administrativas suecas continua a ser um aspecto-chave do sistema de seu governo central, tendo algumas pessoas argumentado que elas se tornaram ainda mais autônomas nos últimos anos. Foi concedido às agências, principalmente, maior controle sobre a administração de recursos humanos, a organização interna e os investimentos em Tecnologia da Informação e em instalações físicas. Essa maior autonomia também foi aumentada, diz-se, pela criação de agências maiores por meio de um processo de fusões (Swedish Agency for Administrative Development, 1999).

No entanto, ao mesmo tempo tem ocorrido fortes movimentos no sentido de reforçar alguns aspectos do controle central, com novos controles financeiros e tetos orçamentários introduzidos pela nova Central Government Administration in the Citizens' Service Act (Lei da Administração de Serviço aos Cidadãos, de 1998).

\section{Estados Unidos da América}

A implementação da GPRA está sujeita a um processo contínuo de melhoria por meio do exame dos planos de desempenho das agências e da emissão de relatórios, tanto pelo Congresso quanto pelo GAO. Embora as fundamentadas análises do $G A O$ tenham identificado áreas importantes para o aperfeiçoamento, elas também dão conta de significativas áreas onde houve melhoria. Para o ano 2000, esses planos incluem:

- melhor articulação de uma orientação para os resultados;

- progresso na identificação e no tratamento de questões transversais;

- maior ênfase nas consequiências das decisões orçamentárias para o desempenho; 
- mostrar como as estratégias têm a finalidade de melhorar os resultados; e

- melhorar a capacidade dentro das agências para coletar e usar dados sobre desempenho (GAO, Estados Unidos, 1999).

O GAO recomendou ao OMB que se considerasse, seriamente, melhorias em todas essas áreas, e solicitou ao seu diretor que agisse neste sentido. O GAO também sugeriu que as comissões do Congresso continuem a melhorar seu próprio uso dos dados de desempenho em seu exame das agências.

\section{Comentários finais}

$\mathrm{O}$ presente relatório procurou levantar as principais questões em matéria de mensuração do desempenho e de prestação de contas nos oito países estudados. Conforme já observado, há algumas limitações nos dados utilizados (principalmente questões de tradução).

Em cada seção, tentamos sublinhar as principais questões (nos resumos), e não pretendemos repeti-las aqui.

O relatório estará sujeito a consulta com autoridades responsáveis em cada um dos países estudados, a fim de assegurar a exatidão do que foi transmitido.

Este relatório será a base para um sumário menor de temas e questões-chave a serem incluídos no relatório $N A O$ sobre mensuração de desempenho em ministérios do Reino Unido.

\section{| Notas}

* Relatório para o UK National Audit Office (Gabinete Nacional de Auditoria do Reino Unido, 2001, Public Futures Ltd. Disponível, em inglês, no site www.publicfutures.com, sob o título Measuring Performance of Government Departments - international developments.

1 Expressão relativa a serviços ao cidadão em que o atendimento é realizado em balcões ou guichês. 
Glossário de siglas

\section{Austrália}

ANAO - Australian National Audit Office

DOFA - Commonwealth Department of Finance and Administration

FMA - Financial Management and Accountability

SOSR - State of the Service Report

PBS - State of the Public Service

APS - Australian Public Service

\section{Canadá}

SEM - Expenditure Management System

OAG - Office of Auditor-General

TBS - Tresaury Board Secretariat

CCAF - Canadian Comprehensive Audit Foundation

EMS - Expenditure Management System

\section{Dinamarca}

DOAG - Danish Office of the Auditor-General

\section{Estados Unidos}

DOD - Department of Defense

GAO - General Accounting Office

GPRA - Government Performance and Results

NPRG - National Partnership for Reinventing Government

OMB - Office of Management and Budget

SSA - Social Security Agency

VA - Veterans Administration

FDA - Food and Drug Administration

\section{Finlândia}

OPSA - Office of Parliamentary State Auditor

$\mathrm{SAO}$ - State Audit Office

\section{Holanda}

CAD - Central Auditing Department of the Ministry of Finance

\section{Nova Zelândia}

AO - Audit Office

DFR - Departmental Forecast Report

OAG - Office of the Audit General

SPIS - Service Performance Information Systems

SPMCE - Service Performance Management Control Environments

SPOG - Strategic Priorities and Overarching Goals

SRA - Strategic Result Areas

CAD - Capability, Accountability and Performance 
SSP - Statement of Service Performance

KRA - Key Results Areas

\section{Reino Unido}

NAO - National Audit Office

\section{Suécia}

RRV - Reksrevisionsverket - Sweden National Audit Office

SNAO - Swedish Nacional Audit Office

\section{Europa}

EFQM - European Foundation for Quality Management

\section{Referências bibliográficas}

Australian National Audit Office. (1997), Finacial Control and Administration Audit Across Agencies (Audit Report 39), ANAO.

Barret, P.J. (2000), Managing Compliance for Assurance and Performance: Setting the Course - Integrating Conformance with Performance (Speech by the Auditor-General for Australia).

Department of Finance and Administration. Attorney-General's Department; Australian Competition and Consumer Commission: Joint Seminar. Canberra: ANAO Website.

Controller and Auditor-General. (1999), Government Departments - Results of the 1998-99 Audits. Wellington: OAG.

Controller and Auditor-General. (1999), Third Report for 1999: The Accountability of Executive Government to Parliament. Wellington: OAG.

Department of Finance. (1992), The role of Evaluation in Decision Making in the 1991-92 Budget Context. Canberra: Department of Finance.

Department of Finance. (1994), The Use of Evaluation in the 1993-94 Budget. Canberra: Department of Finance.

Department of Finance. (1995), The Use of Evaluation in the 1994-95 Budget. Canberra: Department of Finance.

Department of Finance and Administration. (1998), Specifying Outcomes and Outputs. Canberra: DOFA — Budget Group.

Department of Finance and Administration. (1999), Outcomes and Outputs (Nov.1999). Canberra. DOFA — Budget Group.

General Accounting Office. (1999), Managing for Results - Opportunities for Continued Improvements in Agencies Performance Plans. Washington DC: General Accounting Office (USA).

Joint Committee of PublicAccounts And Audit. (2000), Review of the Financial Management and Accountability Act 1997 and the Commonwealth Authorities and Companies Act 1997. Canberra: Parliament.

National partnership for Reiventing Government. (1999), Balancing Measures: Best Practices in Performance Management. Washington DC: National Partnership for Reiventing Government (USA).

Neale, A., Daken, L. (2000), Streamlining Non-Financial Performance Reporting. Public Sector Performance 2000, Wellington, New Zealand. 
Oecd-Puma. (1996), Performance Auditing and the Modernisation of Government. Paris, OECD.

Oecd-Puma. (1997), In Search of Results: Performance Management Practices. Paris, OECD.

Office of the Auditor-General. (2000), Roles and Functions of the OAG. Wellington: OAG.

Pollit, C., Bouckaert, G. (2000), Public Management Reform - A Comparative Analysis. Oxford: Oxford University Press.

President of the Treasury Board (CAnada). (1999), Managing for Results 1999, vol.1. Ottawa: TBS.

Sarpetta, S., Bassanini, A. et al. (2000), Economic Growth in the OECD Area - Recent Trends at the Aggregate and Sectoral Level. Paris: OECD.

Senate Finance and Public Administration Legislation Committee. (2000), The Format of the Portfolio Budget Statements. Canberra: Parliament.

Swedish Agency for Administrative Development. (1999), The Swedish Central Government in Transition 1999. Stockolm: Statskontoret.

Swedish National Audit Office (Rrv). (1999), Handbook in Performance Auditing Theory and Practice, 2 ed. Stockolm: Riksrevisionsverkett. 


\section{A mensuração do desempenho de ministérios e agências de governo: evoluções internacionais}

Colin Talbot, Lyn Daunton e Colin Morgan

Este artigo apresenta uma análise comparativa sobre as evoluções nos mecanismos de mensuração de desempenho e de prestação de contas dos resultados de ministérios e agências de governo em oito países: Austrália, Canadá, Dinamarca, Estados Unidos, Finlândia, Holanda, Nova Zelândia e Suécia. Trata-se de um relatório preparado para o Gabinete de Auditoria do Reino Unido, e que explora comparativamente um importante conjunto de questões relacionadas à mensuração de desempenho e à publicização dos resultados obtidos, tais como: quem são os responsáveis pela mensuração do desempenho e a prestação de contas; quais são os objetivos gerais da mensuração de desempenho e dos sistemas de prestação de contas; o que está sendo mensurado e quais os tipos de medidas que estão sendo adotadas; se estão sendo adotados mecanismos de mensuração de desempenho para atividades transversais (atividades cujos resultados são de responsabilidade de mais de uma organização ou nível de governo); como é assegurada a qualidade das informações obtidas; quem pode ser responsabilizado pelo desempenho; como e para quem o desempenho obtido é reportado publicamente; além de indicar os principais desenvolvimentos recentes sobre o tema.

\section{La mensuración del desempeño de los ministerios y agencias de gobierno: evoluciones internacionales}

\section{Colin Talbot, Lyn Daunton y Colin Morgan}

Este artículo presenta un análisis comparativo sobre las evoluciones en los mecanismos de mensuración de desempeño y de prestación de cuentas de los resultados de ministerios y organizaciones públicas en ocho países: Australia, Canadá, Dinamarca, Estados Unidos, Finlandia, Holanda, Nueva Zelanda y Suecia. Tratase de un relato preparado para el Gabinete de Auditoría del Reino Unido, y que explora comparativamente un importante conjunto de questiones relacionadas a la mensuración del desempeño y la publicación de los resultados obtenidos, tales como: quien son los responsables por la mensuración del desempeño y la prestación de cuentas; cuales son los objetivos generales de la mensuración del desempeño y de los sistemas de prestación de cuentas; lo que está siendo mensurado y cuales los tipos de medidas que están siendo adoptadas; sí están siendo adoptados mecanismos de mensuración de desempeño para las actividades transversales (actividades cuyos resultados son de responsabilidad de más de una organización o nivel de gobierno); como es asegurada la qualidad de las informaciones obtenidas; quien puede ser responsabilizado por el desempeño; como y para quien el desempeño obtenido es reportado publicamente; alén de indicar los principales progresos recientes sobre el tema.

\section{Performance measurement of ministries and agencies of government: international evolutions}

Colin Talbot, Lyn Daunton and Colin Morgan

This article presents a comparative analysis about the evolutions in the mechanisms of performance measurement and accountability of ministries and public agencies in eight countries: Australia, Canada, Denmark, United States, Finland, Netherlands, New Zealand and Sweden. It presents a report prepared for the United Kingdom Audit Office which
Ano 52

Número 3

Jul-Set 2001

Colin Talbot, Lyn Daunton e Colin Morgan são professores de Política Pública e de Administração da Universidade de Glamorgan, País de Gales, Reino Unido. 
comparativily explores an important set of questions related to performance measurement and the publication of accomplished results such as: who is accountable for performance measurement; which are the general objectives of performance measurement; what is being measured and which kinds of measures are adopted; if mechanisms of performance measurement are being adopted in transversal activities (activities which results are responsibility shared by more than an organization or government level); how the quality of obtained information is assured; who can be accountable for performance; how and who is performance reported for; besides indicating the main recent developments on the subject. 